\title{
A comparative study on nutritional status of Bharno block and Gumla block adult tribal women in rural areas of Gumla district (Jharkhand)
}

\author{
SHEETH Toppo
}

\begin{abstract}
A comparative study was done to know the nutritional status of Bharno block and Gumla block adult tribal women of all income group of rural areas of Gumla district Jharkhand. Family monthly income, education, size, meal pattern, custom and traditions showed positive influence on nutritional status of people of all age groups in both tribal population. The subjects from Gumla block tribal group showed lower intake of protein and calorie as compared to Bharno block tribal group but both the groups showed lower intake of protein, fat, carbohydrate and calorie when compared with ICMR recommended allowance. The prevalence of nutritional deficiency diseases found among these people indicated that the food consumed by them have poor quality or inadequate to meet their growing needs. The study revealed that there is a direct correlation exists between the adequacy of diet and socio-economic status. Diet and nutrition are important factors in the promotion and maintenance of good health. Health and nutritional status of an individual depends on the food they eat. The components of the diet must be chosen judiciously to provide all the nutrients needed in adequate amounts and proportions. A normal balanced diet must include daily foods from the various food groups in sufficient amounts to meet the needs of an individual. Selection of foods from the different food groups also results in variety in the diet, which not only ensures nutritional adequacy but also increases food acceptability. Food habits are an important part of our diet which affects the amount and type of food consumed and thus the nutritional status of the women. The diets of both the group tribal women were mainly based on cereals and deficient in vegetables and fruits. The low intake of these protective foods resulted in nutritional disorders. The clinical signs of malnutrition, anaemia and vitamin B-complex deficiencies were observed. Promoting healthy diets and lifestyles to reduce the burden of malnutrition and non-communicable diseases requires a multisectorial approach. The health and nutritional status of rural women who form the vulnerable group of India's population is far from satisfactory. In the rural areas of Gumla district adult tribal women, they work as homemakers, farmers, food providers, fuel gatherers and animal feeders. Keeping this in mind, the present study has been undertaken. The over all result of this study is that the nutritional status of the womens of both the block area is not so good. It is moderate and some nutritional correction is required. Even having good income, tribal people used to practice their old eating habits and old cooking methods. Thus, they must be provided with proper nutrition education programme and educate them about proper health, hygiene and improved cooking practices so that they can develop themselves and maintain their health in good condition.
\end{abstract}

Key Words : Comparative, Nutritional status, Rural areas, Adult tribal women, RDA(Recommended dietary allowance)

How to cite this article : Toppo, Sheeth (2016). A comparative study on nutritional status of Bharno block and Gumla block adult tribal women in rural areas of Gumla district (Jharkhand). Food Sci. Res. J., 7(2): 176-183, DOI : 10.15740/HAS/FSRJ/7.2/176-183. 